\title{
The pervasive role of accounting and accountability during the COVID-19 emergency
}

Accounting and accountability during

Giulia Leoni

Department of Economics and Business Studies (DIEC), Università degli Studi di Genova, Genova, Italy

Alessandro Lai and Riccardo Stacchezzini

Department of Business Administration, University of Verona, Verona, Italy

Ileana Steccolini

Business School, University of Essex, Colchester, UK

Stephen Brammer

University of Bath, Bath, UK

Martina Linnenluecke

Centre for Corporate Sustainability and Environmental Finance,

Macquarie University, Sydney, Australia, and

Istemi Demirag

Department of Business Administration, School of Business and Governance,

Tallinn University of Technology, Tallinn, Estonia

\begin{abstract}
Purpose - This paper introduces the second part of a AAAJ special issue on accounting, accountability and management during the COVID-19 emergency. The authors analyse the themes that emerge from the second part of the special issue, which allows us to identify the diverse accounting and accountability practices across different geographical and organisational contexts. The authors also provide an overall picture of the contributions of the special issue, with insights into avenues of future research.

Design/methodology/approach - Building on the first part of the AAAJ special issue, the paper draws together and identifies additional emerging themes related to research into the COVID-19 pandemic and how it impacts accounting, accountability and management practices. The authors reflect on the contributions of the special issue to the interdisciplinary accounting research project.

Findings - The authors identify two macro-themes and outline their contributions to the accounting literature. The first deals with the changes and dangers of accounting and accountability practices during the pandemic. The second considers accountability practices in a broader sense, including reporting, disclosure and rhetorical practices in the management of COVID-19.
\end{abstract}

(C) Giulia Leoni, Alessandro Lai, Riccardo Stacchezzini, Ileana Steccolini, Stephen Brammer, Martina Linnenluecke and Istemi Demirag. Published by Emerald Publishing Limited. This article is published under the Creative Commons Attribution (CC BY 4.0) licence. Anyone may reproduce, distribute, translate and create derivative works of this article (for both commercial and non-commercial purposes), subject to full attribution to the original publication and authors. The full terms of this licence may be seen at http://creativecommons.org/licences/by/4.0/legalcode

The authors are very grateful to the authors who contributed to this special issue and the dedicated referees who made enormous efforts in helping with paper reviews. The authors sincerely appreciated the reviews received that helped improve our commentary. The authors are also particularly thankful to Professor James Guthrie, who provided strong support and valuable suggestions to manage this $A A A J$ special issue successfully. Any remaining errors are the authors' own responsibility.

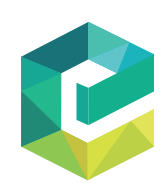

Accounting, Auditing \& Accountability Journal Vol. 35 No. 1, 2022 Emerald Publishing Limited 0951-3574 DOI 10.1108/AAAJ-10-2021-5493 
AAAJ

35,1
Practical implications - The paper shows the pervasive role of accounting and accountability in the unprecedented and indiscriminate health crisis of COVID-19. It highlights the important role of special issues in producing timely research that responds to unfolding events.

Originality/value - This paper contributes to current debates on the roles of accounting and accountability during COVID-19 by drawing together the themes of the special issue and identifying future interdisciplinary accounting research on the pandemic's aftermath.

Keywords COVID-19, Emergency, Crisis, Accounting, Accountability

Paper type Research paper

\section{Introduction}

Since the outbreak of the COVID-19 pandemic in December 2019, various waves of infections have occurred in all parts of the world. Threatening people's health, the pandemic has also seen ongoing lockdown measures that limit personal movement and negatively affect the global economy. At the end of 2020, the positive results of various vaccination programmes began to restore hope of a progressive return to "normal". Mass vaccination campaigns were launched globally in 2021, with a few countries, like the US, the UK, Israel and Europe, leading the race to vaccinate populations, while others lagged, like Australia and New Zealand, as well as several developing countries. The varying success of government vaccination programmes reflects the pressure faced by governments (OECD, 2021), as well as vaccine hesitancy in some countries. Mostly, it demonstrates the inequality in the distribution of the vaccine across "Global North" and "Global South" countries.

At the time of writing, vaccinations rates are increasing globally, and empirical evidence shows the positive effects of the vaccines in terms of reduced case numbers and deaths worldwide (Haas et al., 2021; Ledford, 2021; Public Health England, 2021). More countries can see a glimmer of light at the end of the tunnel, as their citizens return to social interactions, face-to-face education, work in the office and leisure activities.

While the global scenario seems to be improving, the pandemic has changed the course of history, and its implications for society, economy and governments will continue over the long term (Brammer et al., 2020). As guest editors of this $A A A J$ special issue, we believe this second part is not only the conclusion of an insightful journey for the accounting and accountability literature, but also a deep reflection on the role of accounting, accountability and management in times of crisis.

This commentary introduces the second part of the $A A A J$ special issue, which, like the first part, had its origin in a call for papers in May 2020 considering interdisciplinary accounting from a COVID-19 perspective. This second part of the special issue provides an overview of the themes emerging from this second group of contributions. However (Leoni et al.,2021), it all draws some overall insights from the 31 papers included in the special issue, thereby offering some reflections on what we have learnt about the role of accounting, accountability and management practices during this pandemic, as well as some starting points for future research and impact in the aftermath of COVID-19.

\section{The second special issue: emerging themes}

In the first part (Leoni et al., 2021) of this special issue, we provided initial insights into how accounting, accountability and management practices have played a multifaceted role in the COVID-19 pandemic. We identify three main emerging themes. The first is the use of accounting and accountability practices by governments when making extraordinary decisions in response to the pandemic (Mitchell et al., 2021; Ahrens and Ferry, 2021; Ahmad et al., 2021; Ahn and Wickramasinghe, 2021). The second is the use of accounting, numbers and calculative practices by businesses, not-for-profit organisations and charities to navigate the pandemic (Carungu et al., 2021; Velayutham et al., 2021; Delfino and van der Kolk, 2021; 
Passetti et al., 2021; Sargiacomo et al., 2021a; Kober and Thamber, 2021; Huber et al., 2021). The third is the role of accounting in exacerbating existing inequalities during the pandemic (Andrew et al., 2021; Christ and Burritt, 2021; Nikidehaghani and Cortese, 2021).

This second part continues and concludes the special issue with further contributions to the accounting and accountability literature in times of emergencies and crises. The papers in this issue deal with accounting or accountability practices, including disclosure and reporting issues, and highlight not only how such practices have supported the management of the pandemic, but also how they have been misused or have generated negative social outcomes. In so doing, they contribute to widening our perspectives of accounting and accountability practices in society, not just in the time of the pandemic.

While all the papers of this second issue deal with accounting and accountability practices in a broader sense, it is possible to identify two macro-themes emerging from their findings and, in turn, two sub-themes, each focusing on a different perspective of the macro-theme.

The first macro-theme regards the changes and dangers observed in accounting and accountability practices during the COVID-19 crisis. A first sub-theme focuses on how accounting and accountability practices had to change and adapt, thereby changing objects and objectives, following new rules, shifting responsibilities and using new means. A second sub-theme highlights the dangers arising from implementing traditional accounting and accountability practices in the context of a pandemic, thereby warning of the misuse of accounting numbers to limit human action, exacerbate gender issues and reduce moral responsibility.

The second macro-theme is focused on accountability practices in a broader sense, including reporting and disclosure practices, as well as the use of rhetoric, observed during the pandemic. A group of papers within this macro-theme focuses on new forms, contents and means of accountability that have developed because of, or despite, the pandemic. They highlight the success or failure of social media and other digital tools for accountability purposes in public health and human right services, as well as the role of social media in stock markets or in replacing the market with barter. The other group of papers within the second theme relates to different configurations and uses of accountability during the pandemic, from reporting and disclosure to rhetoric and how they were used to create stakeholder engagement and coordination.

\section{An overview of changes and dangers of accounting and accountability practices in times of crisis}

A significant body of new research focuses on accounting practices during the COVID-19 crisis, examining the role of various actors and their use of accounting practices to navigate the crisis. In some instances, accounting practices have changed or adapted to the emergency, adopting alternative tools or means. In other instances, accounting practices have been misused, raising significant concerns about the dangers of such practices. Taken together, this body of literature draws attention to many underexplored aspects of accounting and accountability during times of crisis. Accounting and accountability frameworks, while designed to work under business-as-usual conditions, may not be effective in providing sufficient frameworks for crisis situations that are characterised by decision-making processes that are highly unusual, require unfamiliar decisions and happen in circumstances surrounded by much uncertainty and a lack of clarity regarding future outcomes.

\section{Changing and adapting accounting and accountability practices in times of crisis}

A first group of papers from this special issue points towards important changes and adaptation in accounting practices that occurred because of COVID-19, many of which might spark significant changes and innovations in the field. They all point out how the pandemic required adjustments in accounting and accountability practices, in different geographical
Accounting and accountability during

COVID-19 
AAAJ

35,1

and organisational contexts. Such changes and adaptations include specific interventions relating to accounting regulation to take into consideration the effects of the pandemic, the construction of key performance indicators (KPIs) to manage the pandemic, the embracing of paradox theory to improve management control systems during crises and the development of forms of accountability in action in religious NGOs working in the pandemic.

Looking at more technical aspects of financial reporting, Moscariello and Pizzo (2022) study the response by the International Accounting Standards Board (IASB) to COVID-19, specifically regarding the introduction of the COVID-19-Related Rent Concession, which is an amendment to IFRS 16, Leases (a standard that provides guidance on accounting for lease contracts). The impact of COVID-19 meant that lessors were encouraged or even required to provide lease concessions (i.e., lease modifications). The amendment to IFRS 16 was introduced to avoid complex and costly assessment if concessions due to COVID-19 are lease modifications. The authors show that there is a growing reliance on practical amendments to maintain the IASB's legitimacy, to improve standards' flexibility and to strengthen the IASB's ability to respond to the concerns of European political bodies. The authors conclude that the practical response has helped to deal with the broader economic impact of COVID-19 in a timely fashion and has thus helped to limit criticism and controversy surrounding the adoption of IFRS. Overall, the authors conclude that practical actions help to strengthen the acceptance of IFRS, particularly with a view to preserving the IASB's legitimacy in the EU and in an increasingly complex environment.

Parisi and Bekier (2022) explore the role of performance measurement systems in assessing the impacts of COVID-19 in the context of six European cities, showing how accounting played both an "adjudicating" (classifying, measuring, comparing) and a "territorialising" (creating calculable spaces that individuals inhabit) role in managing the pandemic at local and central levels. The authors discuss how KPIs subjected COVID-19 to quantification and evaluation by several organisations involved in enabling European cities' transition towards regenerative practices, based on circular economy principles. In line with the Foucauldian governmentality framework, the paper shows that the perception of the gravity of the pandemic was influenced by the concurrence of central and local KPIs devised to implement central and local programmes.

Kober and Thambar (2022) suggest a new theoretical framework for the study and implementation of management control systems (MCS) in organisations. Although well known, paradox theory is not widely used in the accounting literature. However, the authors demonstrate its usefulness in setting MCS in situations of crisis or emergency, thanks to its "both/and" rather than "either/or" approach. In so doing, they demonstrate how such an approach can improve MCS to include a more encompassing temporal approach to the management of critical situations, thereby helping organisations survive crises. The authors argue that MCS can be used to simultaneously manage short-term and long-term (or strategic) objectives to navigate a crisis and that MCS can and should be mobilised during crises to identify and embrace opportunities.

Finally, Yates and Difrancesco (2022) provide insights into the necessary change in the discharge of beneficiary accountability in a Spanish NGO to provide humanitarian support to homeless beneficiaries. Indeed, they found that beneficiary accountability is mainly provided through the facilitation of social interaction and assistance. The case study provides evidence on how accountability is a flexible instrument that can change rapidly at a time of social distancing. The NGO under investigation moved from a beneficiary-orientated approach to accountability to an interrelated, personal accountability for the volunteers involved. It highlights how the regular practice of charitable action allowed individuals to experience different feelings and emotions than in (otherwise) everyday life, and to discharge their own, personally held, notions of ethical accountability. The case shows how social distancing measures and processes of "self-isolation" have resulted in the erosion of 
traditional accountability to previous beneficiaries, and, with this, volunteers were unable to discharge personally held notions of ethical accountability that are significant for such organisations.

The dangers of accounting and accountability practices in an emergency

Another group of papers raised significant concerns about the implementation of accounting practices and their dangerous implications for society, morality and freedom. Indeed, there are growing concerns about how governments handled the pandemic outbreak, and how organisations responded in terms of managing, deploying and protecting their workforce. Important themes that emerge from this new body of literature are the misuses of accounting and accountability that emerged during the crisis. These papers all highlight the limits of accounting and accountability practices. Among the negative impacts of these practices, the papers point to the legitimisation of irresponsible actions (Sian and Smyth, 2022), the diffusion of fear (Antonelli et al., 2022), the prioritisation of profit over vulnerable workers, the lack of moral considerations by the Big Four when reassuring stakeholders and the exacerbation of the gender divide.

Sian and Smyth (2022) examine the challenges to public accountability during emergencies, studying the UK government's procurement of personal protective equipment (PPE) under the UK Coronavirus Act 2020, which allowed the UK government to assume emergency powers in key areas such as healthcare, travel and education. While the Act allowed the government to act quickly in terms of procuring goods and services without a lengthy tender process, it also suspended traditional accountability mechanisms and parliamentary scrutiny. The authors conclude that public accountability mechanisms were compromised during the pandemic in the UK but show the importance of other forms of public accountability through active and engaged civil society actors. In the UK context, these actors intervened to hold the government accountable, ultimately leading to calls for a public inquiry into how decisions by the UK government contributed to the significant death rate in the country.

Nonetheless, there is a role for accounting and accounting experts to provide input into governmental strategies to address COVID-19, as demonstrated by Antonelli et al. (2022) in the context of Italy. The authors show how accounting information has been used to ensure support for extreme government actions. In particular, the study draws attention to how accounting provides justification for measures that are promoted apparently as provisional, but that have lasting and enduring effects, first and foremost the ability of governments to suspend the rights of individuals, which may continue beyond a time of crisis. The paper shows how accounting can influence people's behaviour and help develop a permanent state of exception, increasing increases government power. The study raises many important questions for future research around the role of accounting in public accountability, as well as the intersection of political interests and accountability.

Haque et al. (2022) also examine the importance of other forms of accountability by examining the response of non-governmental organisations (NGOs) to the rhetoric of global fashion retailers during the seven months of the pandemic (January-July 2020). The authors show how the NGOs were crucial in exposing retailers' lack of transparency and responsibility regarding their protection of vulnerable workers who are often located in the Global South. The authors demonstrate how global retailers use rhetorical tactics (manipulation, flawed justification, avoidance or silence) when addressing the issues of basic workers' rights during the crisis. The counter-rhetoric by NGOs focused on exposing structural injustice and inequalities and the greater vulnerability of workers during the pandemic. Importantly, the authors conclude that neoliberal corporate transparency policies (including social disclosures or social audits) have been ineffective at countering the fashion
Accounting and accountability during COVID-19

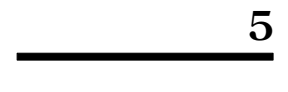


AAAJ

35,1

6

retailers' actions, thus raising questions regarding the value of these practices during crises periods.

The theme of potentially adverse outcomes of neoliberal practices is also explored by Safari et al. (2022), who examine the response of a Big Four firm to the COVID-19 crisis through a lens that examines moral and ethical issues. By focusing on vignettes, the authors found that Big Four employees are dehumanised and depicted as resources rather than persons. Indeed, by completing their tasks, employees become added value for the organisation according to traditional neoliberal ideologies (Safari et al., 2022). The authors voice concern that practices aimed at redundancies and cost considerations were potentially reassuring to some stakeholders but may have undermined the profession's ability to show care towards others.

Perray-Redslob and Younes (2022) explore the intersection of accounting, gender and crisis and investigate the use of accounting tools to address the gendered division of labour during the COVID lockdown in France. The lockdown period saw many couples aspiring for some form of gender equality while coping with the impact of the lockdown, with the result that they used accounting tools (lists, schedules and charts to allocate household tasks), often leading to significant tensions. The authors suggests that these tensions arose because the tools that were used failed to capture the necessary emotional work in times of crisis. The authors suggest that it is important to make emotional work visible, not just at household but also at organisational and societal levels, and that the display of emotional work is crucial for resilience in times of crisis.

\section{Widening the contents, tools and formats of accountability practices during the pandemic}

In a recent editorial in their special issue on (Public) Values, Bracci et al. (2021, p. 1520) observed that

COVID-19 however has increasingly exposed the heterogeneity of our societies, and the plurality and trade-offs between values (health vs economy, egalitarianism vs elitism, no-vax vs pro-vax, prioritisation of individual vs community, full transparency vs privacy, individual freedom vs collective safety, transparency vs effectiveness). This is even made more evident by the expansion of our digital lives through social media, which are allowing an unprecedented expansion in the forms and modes of information and communication, and of expression of diverging interests and values.

They also encouraged scholars to advance their "reflections on accounting for (public) value(s) and to devote more attention to the pluralism of societal as well as public and administrative values and their possible implications for accounting, accountants, reporting and financial management” (p. 1521).

A series of papers in this special issue follow in these footsteps, pointing to the ways in which widening and deepening the content and format of accountability allows an accounting for a plurality of interests and values, as well as the potential to reach wider audiences.

\section{Social media and digital tools as new means of accounting and accountability in a crisis}

Several papers specifically offer new insights into the ways in which social media and digitalisation contribute to widening the scope of accounting and accountability, and in making their performativity and effects potentially stronger.

More specifically, Finau and Scobie (2022) use a netnographic approach to look at how social media is used to facilitate barter and determine the value of exchanged goods. Interestingly, they show how the emergence of a new barter economy in Fiji was not only a response to a crisis but also a way to re-interpret traditional community values of kinship and 
reciprocity, considering the difficulties brought about by the pandemic. This case provides further evidence of how crises may become moments where accounting can be liberated from reductionist and narrow economic foci, showing its potential to represent, interpret and promote new or renewed values, such as solidarity and reciprocity, typical of indigenous communities. This potential of expansion not only widens forms of accounting and accountability but also translates into more effective ways of managing exchange of goods, especially in times of crisis.

Along similar lines, Li et al. (2022) provide evidence of new forms of accountability, which become performative in renewing attention on human rights in the garment industry. The authors draw on Latour's work to look at the case of the Business and Human Rights Resource Centre (BHRRC), and its role in providing a digital platform for dialogues of accountability during the COVID-19 pandemic. The authors find that the accountability enacted on the platform cannot be simplistically seen as forms of counter-accounts. Rather, they operate in three forms: political, organisational and moral. In a political form, the platform contributes to "create" a public interested in human rights issues and shapes the ways in which the public looks at, makes sense of and feels responsible for, them. In the organisational form, the platform supports (re)organising business corporations around respect for human rights, facilitating self-reflection and the adoption and maintenance of practices that are respectful of human rights. In the moral form, the platform keeps organisations accountable without giving this accountability any "closure"; ethics are continuously alive.

Lazzini et al. (2022) contribute to a better understanding of the role of social media forms of communication in shaping and being shaped by financial markets. Drawing on Baudrillard's simulacra and hyperreality theory, the authors look at the relationship between Twitter conversations and Italian stock market trends during the first phase of the COVID-19 pandemic. In the face of increasing exposure to information, social media is becoming increasingly central not only to information and communication but also for sense-making, interpreting reality and sharing emotions. The lockdown placed social media at the centre of the enactment of processes. The authors show that the users' feelings and emotions generate a state of hyperreality, which is reflected in the concrete reality of financial markets. This suggests that social media allows the creation of a hyperreality, in itself a catalyst for emotions and sense-making processes that increasingly shape and are shaped by the "real world" of financial markets.

Finally, Landi et al. (2022) draw on dialogic accounting and citizen engagement perspectives to explore how public health agencies employed social media during the COVID-19 crisis in Italy, the UK and New Zealand. Their study suggests that social media was extensively used as a communication tool in all three countries, but employed dialogically only in New Zealand, where interaction, rather than mono-directional information, took place more extensively. Interestingly, they also found dialogic forms of accountability seemingly avoided the spread of fake news. Overall, their study points to the benefits for public sector entities of engaging in deeper, dialogical interactions, and to the risks of doing so only partially. It appears that engaging dialogically and effectively requires public agencies to build stronger awareness and competencies, which apparently were lacking in the cases of Italy and the UK.

\section{Disclosure, reporting and rhetoric in the pandemic}

Accounting information communicates accounting measurements, but the effectiveness of this information is also affected by how well it is communicated to appropriate stakeholders. Crovini et al. (2022) show how related media coverage conveyed political attention to poor working, hygiene and housing conditions. They show how risk reporting has become a means to respond to public concerns by improving accountability, providing benefits that 
AAAJ

35,1

8 many organisations are not yet aware of. They do this by showing that, in widening the scope of accountability, legitimisation can be obtained by considering the social relations both within an organisation and its external environment. They contribute to better understanding of how increasing stakeholder engagement improves legitimacy by appropriate risk recognition and reporting and by introducing targeted ad hoc disclosures to respond to the dynamically shifting materiality of risks. Connecting risk management and reporting to the business model (BM) not only helps to improve risk recognition and assessment practices but also enhances the meaningfulness of the disclosed risk information and widening forms of accountability during crisis.

Along with these changing accountability demands, organisations also need to communicate accounting information effectively to their stakeholders using annual reports, sustainability reports and especially interviews, press releases and websites during crisis events (De Villiers and Van Staden, 2011). In this context, the study by de Villiers and Molinari (2022) provides evidence of how organisations and their leaders can enhance accountability to stakeholders during crises and how this can help organisational leaders to learn from the strategies employed by political leaders during the COVID-19 crisis. They examine the communication strategy of the NZ prime minister, comparing it with the communication strategies of the president of the US at the time. The case study outlines some key elements of successful communication strategies to convey accountability to ensure public support by providing accountability through clear, unambiguous and noncontradictory messages that render rules unenforceable. The comparative study between $\mathrm{NZ}$ and the US provides insightful lessons for organisations as communication strategies based on clear, consistent and credible messages, which are needed to legitimise leaders' decisions, convey accountability and ensure that stakeholders conform to the emerging guidelines and rules in times of crisis.

In similar vein, Bui et al. (2022), drawing on Green's (2004) theory of rhetorical diffusion, contends that the NZ government relied largely on the rhetorical appeal of pathos (appeal to emotions), ethos (appeal to a sense of social norms) and kairos (appeal to a sense of urgency). Implementing new practices using rhetoric is possible because rhetoric can change ideological beliefs and emotionally persuade an audience to relinquish the status quo for a new practice (pathos), accepting a new practice as efficient. They show that the government adopted an overwhelming prioritisation of health over economic and social outcomes, arguing that in opting for a lockdown, the government made a trade-off between acting quickly and timely (kairos) and acting based on reliable data (logos). Most of the time, accounting and decision-making use reliable data, which may not be readily available during a crisis because there is no time to gather it. This case provides further evidence of the crucial role of rhetorical skills in managers' ability to elicit support for a new practice, using emotionalisation and moralisation strategies when a situation requires urgency (Demirag et al., 2020). Importantly, it shows the unsustainability of rhetoric in the absence of reliable information and demonstrates the consequences of limited (intermittent) evidence and disregard for accounting/accountability data in public policy decisions under a rhetorical strategy.

However, the pandemic has not always brought about improvements in accountability. In other cases, it may have eroded accountability, as shown by Carnegie et al. (2022) They focus on the financial risks to the Australian higher education system (AHES) using a case study of all eight public universities in Victoria, and by examining their 2019 annual reports and related statements. Using Laughlin's (1991) Habermasian organisational change diagnosis and focusing on COVID-19 risk disclosures, they show that only a few universities disclose information about any risks to international student fees associated with COVID-19 in their annual reports. Those included were in a standard qualitative and neutral form and displayed no material content. Their analysis shows that universities appeared to be unaware of, 
or reluctant to discuss, the potential financial shocks resulting from the pandemic and the impacts on their staff and students. While some potential losses of income were mentioned in the media, official university documents reveal morphostatic changes undertaken by universities to overcome the risk impacts of COVID-19. Their case study shows further evidence of how the inadequacy of disclosing significant risks in these annual reports provides a sense of false accountability and transparency concerning material risks, which, in turn, is likely to lead to significant operational and social consequences in the university sector in Australia.

Overall, this group of papers reflects on how the pandemic has, in some cases, brought about stronger and new, emerging forms of engagement with stakeholders, and a widening in the contents, forms and discourses of accountability. In particular, they show the need to acknowledge and further explore the increasing role played by social media and digitalisation in the accounting arena (on this, see also Arnaboldi et al., 2017; Agostino et al., 2021) and to rediscover the importance of assessing and reporting risk, which may become central to the accounting disclosure policies and strategies employed by the public and private sectors, notfor-profit and other social enterprises, and which will have significant operational, social and financial impacts if not coordinated and managed appropriately.

\section{An overall picture of the special issue on COVID-19: concluding remarks and future research}

The present commentary aimed to depict the additional themes emerging from the contributions collected in the second part of the special issue and to provide a comprehensive overview of the main contributions of the two special issues to the accounting, accountability and management literature. In doing so, it also identifies some opportunities for future research.

This second part of the special issue closes an exceptional "adventure" in the interdisciplinary accounting project. The issue is the result of an impressive effort by accounting academics from various parts of the world willing to provide their contribution and insights in - and despite of - a time of great uncertainty and emergency. The 175 initial submissions from 33 different countries and the final 31 papers contributing to this special issue are tangible proof of the incredible commitment shown by the interdisciplinary accounting community to making an impact through research. For this, we thank this strong academic community that has responded to our call. And we are incredibly grateful to the two editors-in-chief for entrusting us with this important task.

Facing the historical moment that is this pandemic, our shared intent as guest editors has been to provide a timely contribution that brings deep and lasting insights into the role of accounting, accountability and management. We hope that the research in this special issue also informs practitioners, businesses, organisations and governments about the benefits and risks of accounting and accountability during emergencies.

We are aware that a growing body of accounting literature since the early 2000s has investigated the role of accounting, accountability and management systems in times of financial crises, natural disasters or humanitarian emergencies (Bracci et al., 2015; Barbera et al., 2016, 2017, 2020, 2021; Sargiacomo et al., 2021b; Sargiacomo, 2014; Lai et al., 2014; Linnenluecke, 2017; McKnight and Linnenluecke, 2019; Perkiss and Moerman, 2017; Matilal and Adhikari, 2019). The 31 papers that form this special issue provide a comprehensive and multifaceted contribution to this literature, as well as to the accounting literature more generally. They extend our knowledge of the nature of accounting, accountability and management practices.

This health crisis is global, not just in a geographical sense, but because it has impacted everyone and everything, across institutions, organisations, governments, businesses and society. Everything has changed. Table A1 shows how accounting and accountability

Accounting and accountability during

COVID-19

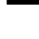


AAAJ

35,1

practices around the world have changed, failed, succeeded and damaged or exerted power due to, or despite, the pandemic in diverse types of organisations, government and society.

Table A1 lists the contributions from the two special issues, providing not only an overview of the themes covered by the two issues but also clear evidence of the variety of the contexts and organisations where accounting and accountability practices have been implicated in the management of the pandemic. As such, it is evident that human beings - no matter in what capacity - turn to accounting, thanks to its multipurpose nature and malleability (Potter, 2005; Leoni, 2021). Indeed, if one considers that emergencies and critical events are multifaceted, it is not surprising that their management and solutions are entrusted to a multipurpose instrument, such as accounting.

The various contributions show how, in some instances, people using accounting and related practices to adapt and change in ways improve its capacity to manage, aid decisionmaking, exert control and solve problems. However, in other instances, the research in this issue has found that accounting is not always adapted to improve society but to impose unwanted surveillance, restrict personal freedom, worsen the living conditions of the weak and the poor and exacerbate existing social issues.

While the contributions offer a wide variety of theoretical perspectives, are set in very different geographical and organisational contexts and provide diverse results, they have one thing in common. They all show how accounting is a pervasive practice in all human activities, institutions and organisations, no matter the geographical location, the specific circumstance - such as a global pandemic - or the targeted objective.

We think that this special issue contributes to the interdisciplinary accounting research in several ways. First, when we released our call for papers in May 2020, the world was still attempting to make sense of the COVID-19 pandemic and its implications for human life, education, economy, policies and organisations. Facing this uncertain scenario, our call for papers has been intentionally left as broad and open as possible to attract contributions from different countries and different organisational contexts, about different objects and practices, hoping for heterogenous findings and innovative contributions to the accounting, accountability and management literature. At the end of this journey, we argue that this issue has achieved this aim, confirming the multipurpose and interdisciplinary role of accounting and accountability.

Second, this issue collects research that reflects the situation of the first months after the COVID-19 outbreak (December 2019-September 2020) and therefore depicts the initial responses and reactions to the pandemic by different types of organisations and institutions in different contexts and countries, with their implications for individuals, organisations and governments. At the time of writing, the global scenario has changed greatly and generally improved, thanks to the human ability to respond to crisis, adapt, research and find solutions. We are aware that human ability is often supported by accounting and its calculative and management practices. Thus, we believe that our special issue contributes to the emergence of an important stream of research that has the chance to positively impact the future of accounting and accountability practices after COVID-19.

Third, in agreement with the editors, we expedited the special issue so as to break the academic journal traditions of lengthy time frames for reviews and publication, as we are aware that an emergency calls for immediate responses, ideas and contributions. Of course, we strongly believe that research requires time, reflection, rigour and external reviews, but for it also to impact practice, professionals, governments and regulatory bodies, as well as society, it needs to be timely. Indeed, we believe that the contributions included in this special issue are impactful because they open new and relevant avenues of much needed research about accounting, accountability and management.

Finally, we believe that this issue contributes to opening new avenues of future research. As the pandemic has evolved, more questions arise. Are we going back to life before COVID-19? Or has the world profoundly changed and how? What will be the role of 
accounting, accountability and management practices in the world after COVID-19? What are the lessons learned from this global crisis? How are we going to implement these lessons? Can accounting and accountability practices contribute to avoiding something like the pandemic happening again? Are accounting and management practices ready in case of another health emergency? We hope that the interdisciplinary accounting community can find starting points for future research in this special issue that will continue in the aftermath of COVID-19 and that will ask and answer these many questions.
Accounting and accountability during COVID-19

\section{References}

Agostino, D., Saliterer, I. and Steccolini, I. (2021), "Digitalization, accounting and accountability: a literature review and reflections on future research in public services", Financial Accountability and Management, pp. 1-25, doi: 10.1111/faam.12301.

Ahmad, S., Connolly, C. and Demirag, I. (2021), "Testing times: governing a pandemic with numbers", Accounting, Auditing and Accountability Journal, Vol. 34 No. 6, pp. 1362-1375.

Ahn, P.D. and Wickramasinghe, D. (2021), "Pushing the limits of accountability: big data analytics containing and controlling COVID-19 in South Korea", Accounting, Auditing and Accountability Journal, Vol. 34 No. 6, pp. 1320-1331.

Ahrens, T. and Ferry, L. (2021), "Accounting and accountability practices in times of crisis: a Foucauldian perspective on the UK government's response to COVID-19 for England", Accounting, Auditing and Accountability Journal, Vol. 34 No. 6, pp. 1332-1344.

Andrew, J., Baker, M. and Guthrie, J. (2021), “Accounting, inequality and COVID-19 in Australia”, Accounting, Auditing and Accountability Journal, Vol. 34 No. 6, pp. 1471-1483.

Antonelli, V., Bigoni, M., Funnell, W. and Cafaro, E.M. (2022), “Accounting for biosecurity in Italy under COVID-19 lockdown", Accounting, Auditing and Accountability Journal, Vol. 35 No. 1.

Arnaboldi, M., Busco, C. and Cuganesan, S. (2017), "Accounting, accountability, social media and big data: revolution or hype?”, Accounting, Auditing and Accountability Journal, Vol. 30 No. 4, pp. 762-776.

Barbera, C., Guarini, E. and Steccolini, I. (2016), "Italian Municipalities and the fiscal crisis: four strategies for muddling through", Financial Accountability and Management, Vol. 32 No. 3, pp. 335-361.

Barbera, C., Jones, M., Korac, S., Saliterer, I. and Steccolini, I. (2017), “Governmental financial resilience under austerity in Austria, England and Italy: how do local governments cope with financial shocks?”, Public Administration, Vol. 95 No. 3, pp. 670-697.

Barbera, C., Guarini, E. and Steccolini, I. (2020), "How do governments cope with austerity? The roles of accounting in shaping governmental financial resilience", Accounting, Auditing and Accountability Journal, Vol. 33 No. 3, pp. 529-558.

Barbera, C., Jones, M., Korac, S., Saliterer, I. and Steccolini, I. (2021), "Local government strategies in the face of shocks and crises: the role of anticipatory capacities and financial vulnerability", International Review of Administrative Sciences, Vol. 87 No. 1, pp. 154-170.

Bracci, E., Humphrey, C., Moll, J. and Steccolini, I. (2015), "Public sector accounting, accountability and austerity: more than balancing the books?", Accounting, Auditing and Accountability Journal, Vol. 28 No. 6, pp. 878-908.

Bracci, E., Saliterer, I., Sicilia, M. and Steccolini, I. (2021), "Accounting for (public) value(s): reconsidering publicness in accounting research and practice”, Accounting, Auditing and Accountability Journal, Vol. 34 No. 7, pp. 1513-1526.

Brammer, S., Branicki, L. and Linnenluecke, M.K. (2020), "COVID-19, societalization, and the future of business in society”, Academy of Management Perspectives, Vol. 34 No. 4, pp. 493-507. 
AAAJ 35,1

Bui, B., Moses, O. and Dumay, J. (2022), "The rhetoric of New Zealand's COVID-19 response", Accounting, Auditing and Accountability Journal, Vol. 35 No. 1.

Carnegie, G.D., Guthrie, J. and Martin-Sardesai, A. (2022), "Public universities and impacts of COVID-19 in Australia: risk disclosures and organisational change", Accounting, Auditing and Accountability Journal, Vol. 35 No. 1.

Carungu, J., Di Pietra, R. and Molinari, M. (2021), "The impact of a humanitarian disaster on the working approach of accountants: a study of contingent effect", Accounting, Auditing and Accountability Journal, Vol. 34 No. 6, pp. 1388-1403.

Christ, K.L. and Burritt, R.L. (2021), "Accounting for modern slavery risk in the time of COVID-19: challenges and opportunities", Accounting, Auditing and Accountability Journal, Vol. 34 No. 6, pp. 1484-1501.

Crovini, C., Schaper, S. and Simoni, L. (2022), "Dynamic accountability and the role of risk reporting during a global pandemic", Accounting, Auditing and Accountability Journal, Vol. 35 No. 1.

de Villiers, C. and Molinari, M. (2022), "How to communicate and use accounting to ensure buy-in from stakeholders: lessons for organizations from governments' COVID-19 strategies”, Accounting, Auditing and Accountability Journal, Vol. 35 No. 1.

De Villiers, C. and Van Staden, C.J. (2011), "Where firms choose to disclose voluntary environmental information", Journal of Accounting and Public Policy, Vol. 30, pp. 504-525.

Delfino, G.F. and van der Kolk, B. (2021), "Remote working, management control changes and employee responses during the COVID-19 crisis", Accounting, Auditing and Accountability Journal, Vol. 34 No. 6, pp. 1376-1387.

Demirag, I., Firtin, E. and Tekin, E. (2020), "Managing expectations with emotional accountability: making City Hospitals accountable during the COVID-19 pandemic in Turkey", Journal of Budgeting, Accounting and Financial Management, Vol. 32 No. 5, pp. 889-901.

Finau, G. and Scobie, M. (2022), "Old ways and new means: indigenous accountings during and beyond the pandemic", Accounting, Auditing and Accountability Journal, Vol. 35 No. 1.

Green, S.E. (2004), “A rhetorical theory of diffusion”, The Academy of Management Review, Vol. 29 No. 4 , pp. 653-669.

Haas, E.J., Angulo, F.J., McLaughlin, J.M., Anis, E., Singer, S.R., Khan, F. and Alroy-Preis, S. (2021), "Impact and effectiveness of mRNA BNT162b2 vaccine against SARS-CoV-2 infections and COVID-19 cases, hospitalisations, and deaths following a nationwide vaccination campaign in Israel: an observational study using national surveillance data”, The Lancet, Vol. 397 No. 10287, pp. 1819-1829.

Haque, S., Ahmad, N. and Islam, M.A. (2022), “COVID-19 and global clothing retailers' responsibility to vulnerable workers: NGO counter-rhetoric", Accounting, Auditing and Accountability Journal, Vol. 35 No. 1.

Huber, C., Gerhardt, N. and Reilley, J. (2021), "Organizing care during the COVID-19 pandemic: the role of accounting in German hospitals", Accounting, Auditing and Accountability Journal, Vol. 34 No. 4, pp. 1445-1456.

Kober, R. and Thambar, P.J. (2022), "Paradoxical tensions of the COVID-19 pandemic: a paradox theory perspective on the role of management control systems in helping organizations survive crises", Accounting, Auditing and Accountability Journal, Vol. 35 No. 1.

Kober, R. and Thamber, P. (2021), "The role of accounting in shaping charities' financial resilience", Accounting, Auditing and Accountability Journal, Vol. 34 No. 4, pp. 1416-1429.

Lai, A., Leoni, G. and Stacchezzini, R. (2014), "The socializing effects of accounting in flood recovery", Critical Perspectives on Accounting, Vol. 25 No. 7, pp. 579-603.

Landi, S., Costantini, A., Fasan, M. and Bonazzi, M. (2022), "Public engagement and dialogic accounting through social media during COVID-19 crisis: a missed opportunity?", Accounting, Auditing and Accountability Journal, Vol. 35 No. 1. 
Laughlin, R.C. (1991), "Environmental disturbances and organisational transitions and transformations: some alternative models”, Organization Studies, Vol. 12 No. 2, pp. 209-232.

Lazzini, A., Lazzini, S., Balluchi, F. and Mazza, M. (2022), "Emotions, moods and hyperreality: social media and the stock market during the first phase of COVID-19 pandemic", Accounting, Auditing and Accountability Journal, Vol. 35 No. 1.

Ledford, H. (2021), "Six months of COVID vaccines: what 1.7 billion doses have taught scientists", Nature, Vol. 594 No. 7862, pp. 164-167.

Accounting and accountability during COVID-19

Leoni, G. (2021), "Rudimentary capital budgeting for a utopian Italian colony in Australia: accounting as an advocating device", Accounting History, Vol. 26 No. 3, pp. 398-408.

Leoni, G., Lai, A., Stacchezzini, R., Steccolini, I., Brammer, S., Linnenluecke, M. and Demirag, I. (2021), "Accounting, management and accountability in times of crisis: lessons from the COVID-19 pandemic", Accounting, Auditing and Accountability Journal, Vol. 34 No. 6, pp. 1305-1319.

Li, Y., McKernan, J. and Chen, M. (2022), "Turning around accountability”, Accounting, Auditing and Accountability Journal, Vol. 35 No. 1.

Linnenluecke, M.K. (2017), "Resilience in business and management research: a review of influential publications and a research agenda", International Journal of Management Reviews, Vol. 19 No. 1, pp. 4-30.

Matilal, S. and Adhikari, P. (2019), "Accounting in Bhopal: making catastrophe”, Critical Perspectives on Accounting, Vol. 72, pp. 1-24.

McKnight, B. and Linnenluecke, M.K. (2019), "Patterns of firm responses to different types of natural disasters", Business and Society, Vol. 58 No. 4, pp. 813-840.

Mitchell, F., Nørreklit, H., Nørreklit, L., Cinquini, L., Koeppe, F., Magnacca, F., Mauro, S.G., Jakobsen, M., Korhonen, T., Laine, T. and Liboriussen, J.M. (2021), "Evaluating performance management of COVID-19 reality in three European countries: a pragmatic constructivist study", Accounting, Auditing and Accountability Journal, Vol. 34 No. 4, pp. 1345-1361.

Moscariello, N. and Pizzo, M. (2022), "Practical expedients and theoretical flaws: the IASB's legitimacy strategy during the COVID-19 pandemic", Accounting, Auditing and Accountability Journal, Vol. 35 No. 1.

Nikidehaghani, M. and Cortese, C. (2021), "(Job) keeping up appearances”, Accounting, Auditing and Accountability Journal, Vol. 34 No. 6, pp. 1502-1512.

OECD (2021), Enhancing Public Trust in COVID-19 Vaccination: The Role of Governments, pp. 1-27, available at: https://read.oecd-ilibrary.org/view/?ref=1094_1094290-a0n03doefx\&title= Enhancing-public-trust-in-COVID-19-vaccination-The-role-of-governments\&_ga=2.97376799. 1416249961.1638721478-1096310632.1638721478.

Parisi, C. and Bekier, J. (2022), "Assessing and managing the impact of COVID-19: a study of six European cities participating in a circular economy project", Accounting, Auditing and Accountability Journal, Vol. 35 No. 1.

Passetti, E., Battaglia, M., Bianchi, L. and Annesi, N. (2021), "Coping with the COVID-19 pandemic: the technical, moral and facilitating role of management control", Accounting, Auditing and Accountability Journal, Vol. 34 No. 6, pp. 1430-1444.

Perkiss, S. and Moerman, L. (2017), "Hurricane Katrina: exploring justice and fairness as a sociology of common good (s)", Critical Perspectives on Accounting, Vols 67-68, pp. 1-15.

Perray-Redslob, L. and Younes, D. (2022), "Accounting and gender equality in (times of) crisis: toward an accounting that accommodates for emotional work?", Accounting, Auditing and Accountability Journal, Vol. 35 No. 1.

Potter, B.N. (2005), "Accounting as a social and institutional practice: perspectives to enrich our understanding of accounting change", Abacus, Vol. 41 No. 3, pp. 265-289.

Public Health England (2021), "COVID-19 vaccine surveillance report”, Week 34. 
AAAJ

35,1

14
Safari, M., Tsahuridu, E. and Lowe, A. (2022), "Big4 responses to the COVID-19 crisis: an examination of Bauman's moral impulse", Accounting, Auditing and Accountability Journal, Vol. 35 No. 1.

Sargiacomo, M. (2014), "Accounting for natural disasters and humanitarian interventions", Critical Perspectives on Accounting, Vol. 25 No. 7, pp. 576-578.

Sargiacomo, M., Corazza, L., D’Andreamatteo, A., Dumay, J. and Guthrie, J. (2021a), “COVID-19 and the governmentality of emergency food in the City of Turin”, Accounting, Auditing and Accountability Journal, Vol. 34 No. 6, pp. 1457-1470.

Sargiacomo, M., Servalli, S., Potito, S., D’Andreamatteo, A. and Gitto, A. (2021b), “Accounting for natural disasters from a historical perspective: a literature review and research agenda”, Accounting History, Vol. 26 No. 2, pp. 179-204.

Sian, S. and Smyth, S. (2022), "Supreme emergencies and public accountability: the case of procurement in the UK during the COVID-19 pandemic", Accounting, Auditing and Accountability Journal, Vol. 35 No. 1.

Velayutham, A., Rahman, A.R., Narayan, A. and Wang, M. (2021), "Pandemic turned into pandemonium: the effect on supply chains and the role of accounting information", Accounting, Auditing and Accountability Journal, Vol. 34 No. 6, pp. 1404-1415.

Yates, D. and Difrancesco, R.M. (2022), "The view from the front line: shifting beneficiary accountability and interrelatedness in the time of a global pandemic", Accounting, Auditing and Accountability Journal, Vol. 35 No. 1.

\section{Corresponding author}

Giulia Leoni can be contacted at: giulia.leoni@unige.it 


\section{Appendix}

Accounting and

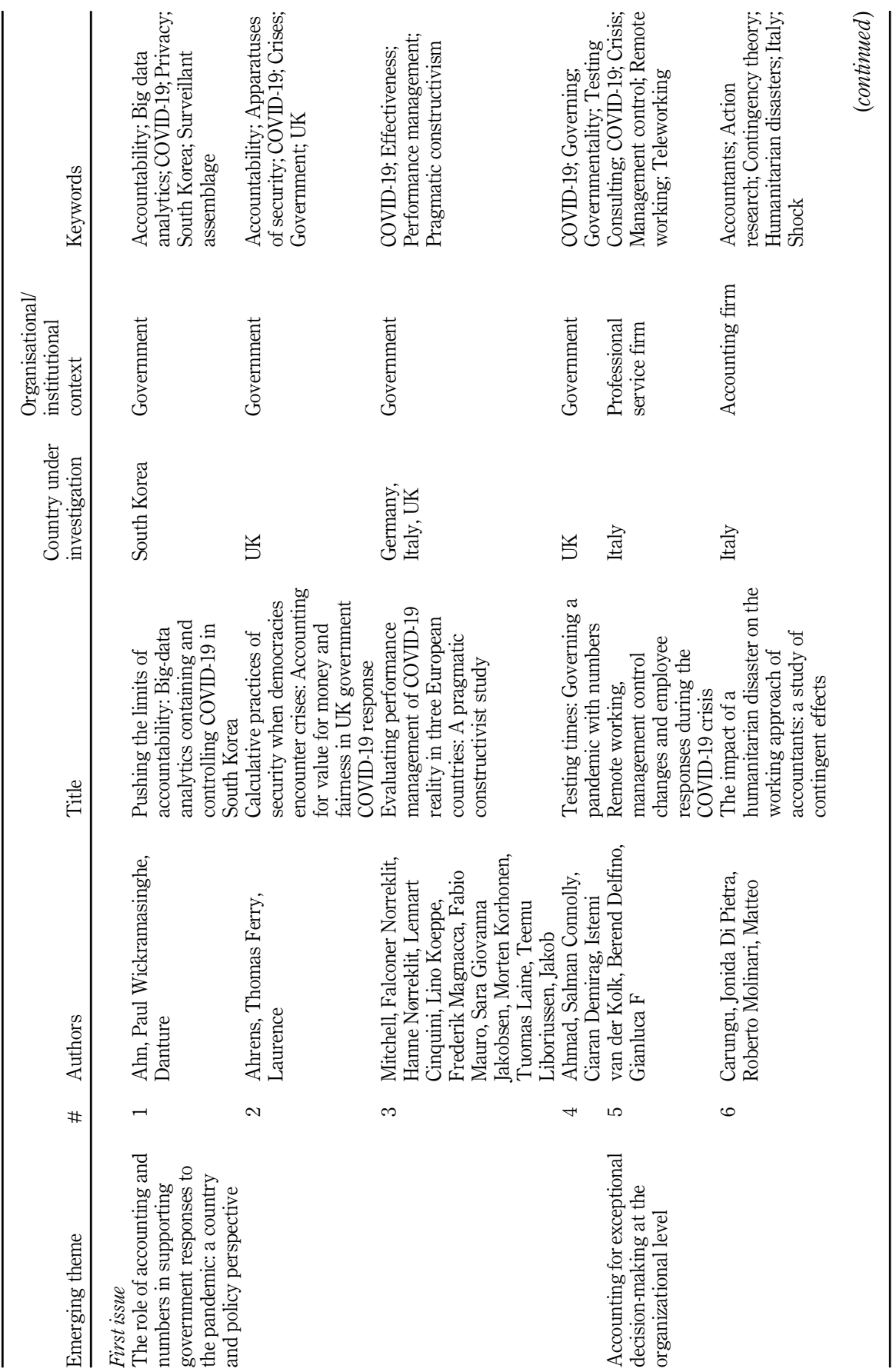

accountability during

COVID-19

15

Table A1.

Complete list and details of the AAAJ Covid-19 special issue articles 
AAAJ
35,1

16

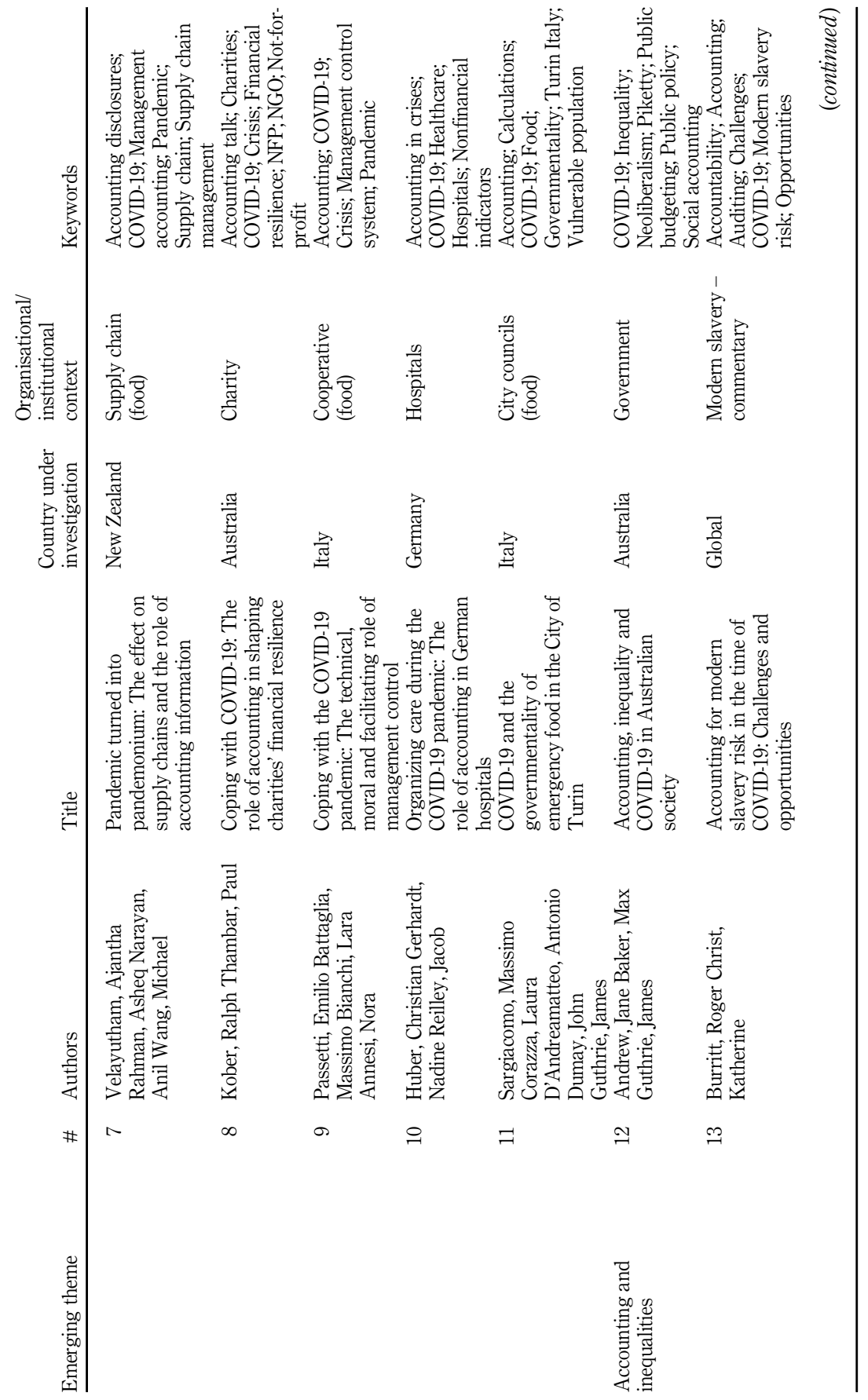

Table A1. 


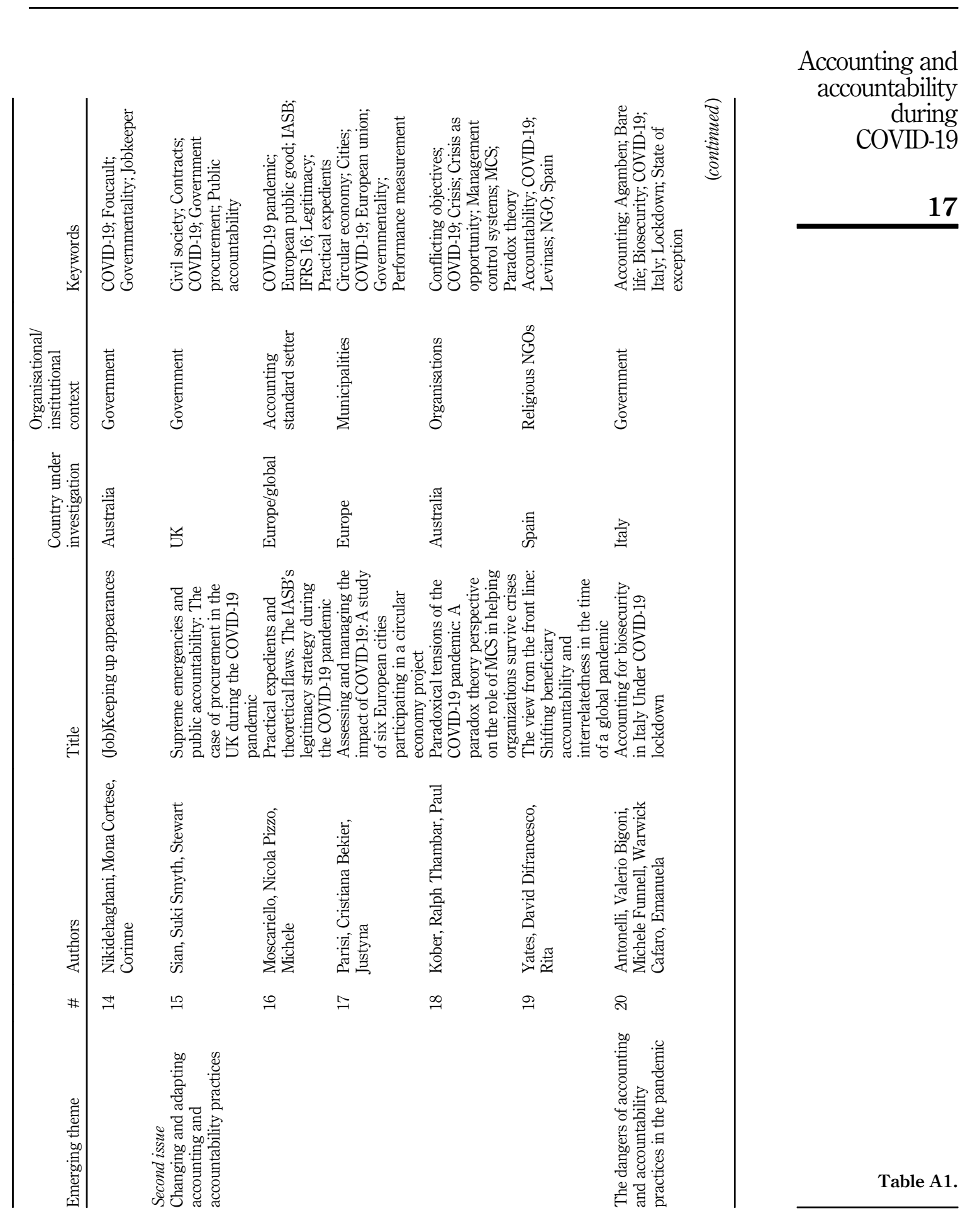


AAAJ
35,1

18

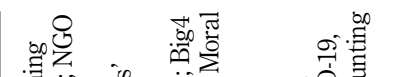

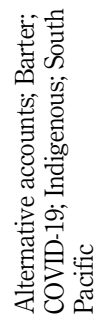

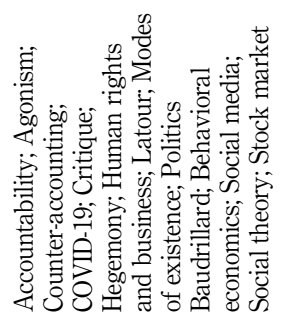

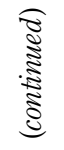

증

过记

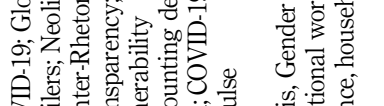

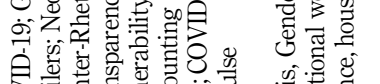

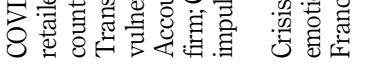

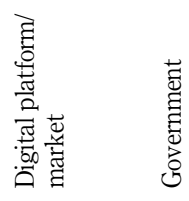

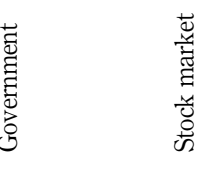

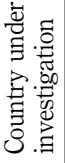

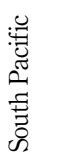

苋

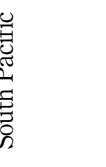

占

炡

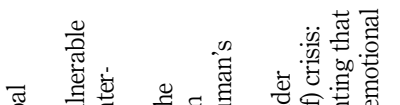

宅

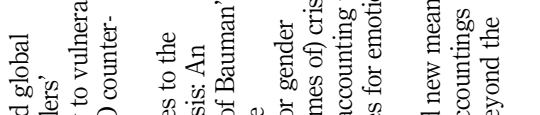

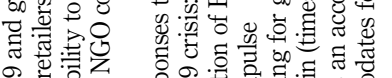

은

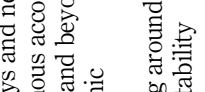

竞:

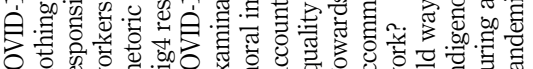

音总

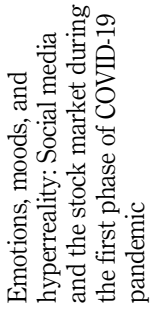

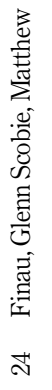

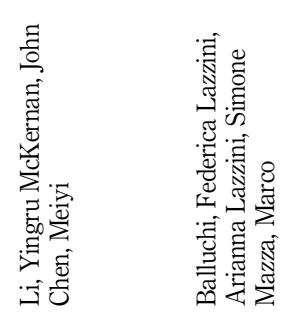

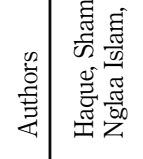

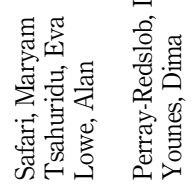

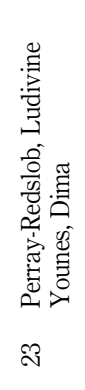

\#

ลิ

$\stackrel{2}{\sim}$

จ

Table A1.

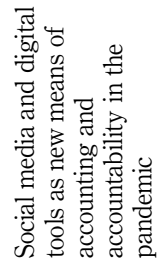




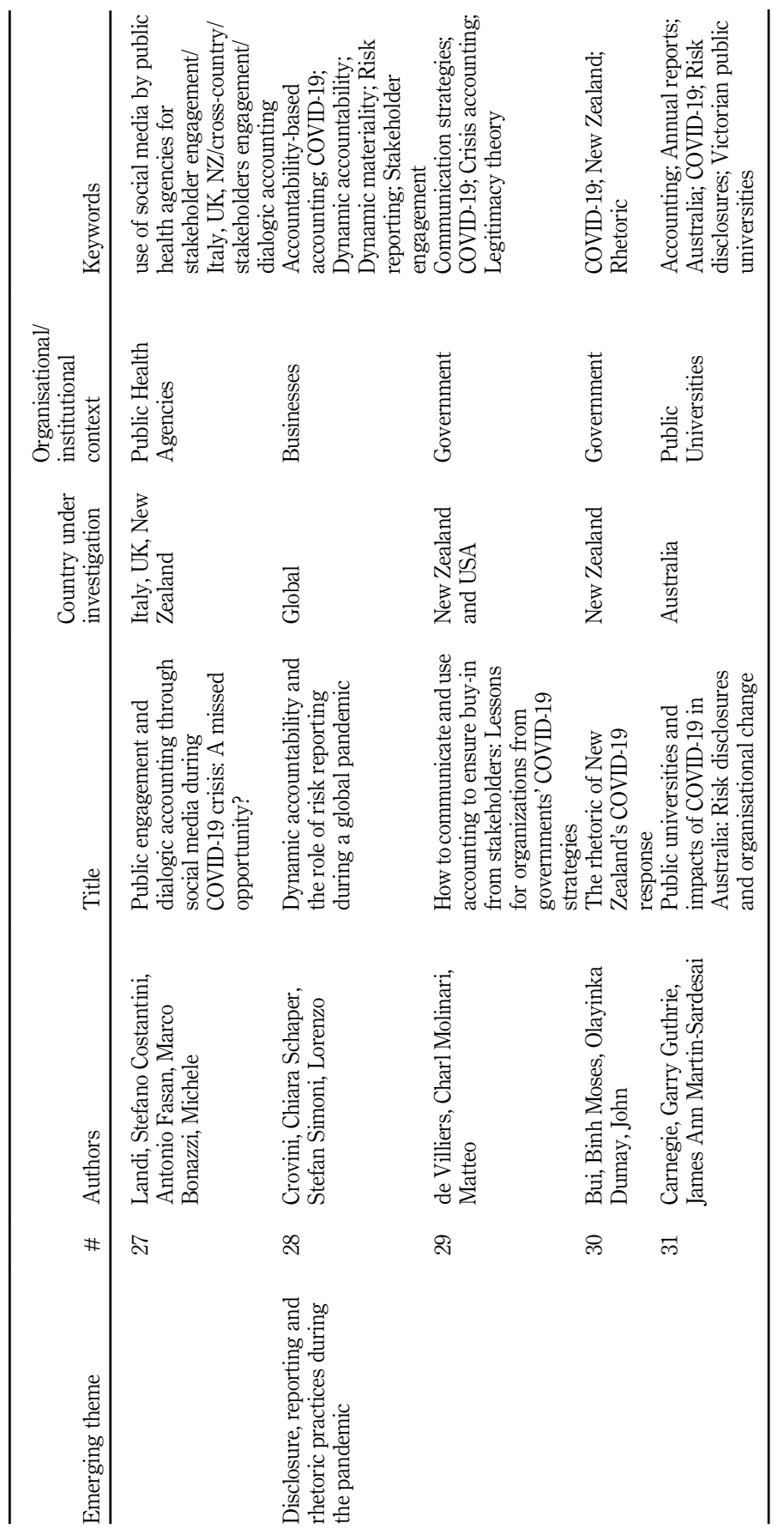

Accounting and accountability during COVID-19

19

Table A1. 